\title{
Adaptation to climate change in Kazakhstan using data from space monitoring of snowmelt
}

\author{
Aknur Zholdasbek ${ }^{1}$, and Azamat Kauazov ${ }^{2, *}$ \\ ${ }^{1}$ Al-Farabi Kazakh national university, faculty of geography and environmental sciences, Almaty, \\ Republic of Kazakhstan \\ ${ }^{2}$ RSE "KazHydroMet” (National weather service), Research Department, Nur-Sultan, Republic of \\ Kazakhstan
}

\begin{abstract}
The present article is concerned with the applied aspects of applying the results of space monitoring of snow cover, in particular, it is proposed to present the results of the analysis in the form of specialized bulletins. The purpose of this publication is to present the available results of space monitoring of snow cover in Kazakhstan as an element of adaptation to climate change. A three-level system of space monitoring of snow cover is proposed, which includes three technological complexes: operational mapping of snow cover boundaries; monitoring of seasonal snow cover dynamics; analysis of long-term snow cover dynamics. A map of snow melting in Kazakhstan in 2020, the dynamics of long-term changes of snow covered area, as well as methods for analyzing the spatialtemporal distribution of snow cover and formats of special bulletins are presented. It is most appropriate to present the results of space monitoring of snow cover in a complex, maximally generalized form (product). The results of the work can be applied in the scientific, industrial and educational spheres to adapt and increase resistance.
\end{abstract}

\section{Introduction}

Snow cover plays a significant role in the climate system, in emergencies, and in agriculture. The range of applications of snow cover data is extremely broad. Initially, the most accessible task for remote sensing from space was to monitor snowmelt. Regular space monitoring of snowmelt has been carried out in Kazakhstan since 2000. Certain results have been achieved in the field of seasonal and long-term monitoring of snow cover according to the remote sensing data [1;5]. In practical terms, the results of snowmelt monitoring can be used in important applications: assessment of global climate change, to control the passage of spring floods in regions with a high risk of flooding, assessment of agricultural risks taking into account the impact of weather conditions (assessment of productive moisture reserves in the soil, assessment of the probability of dry conditions). The last appendix is of particular importance for non-irrigation grain cultivation areas in the Northern regions of Kazakhstan, since spring soil moisture is a key factor determining the yield of grain crops. A number of studies $[6,7]$ have shown the possibility of forecasting

\footnotetext{
*Corresponding author: kauazov_a@meteo.kz
} 
droughts based on the height and position of the snow cover boundary in the spring period. The author [7] found that severe droughts are observed after the early snow melting. On the contrary, when there was a late snowmelt (the snow cover borders are South of the usual one), there was no drought, and the late snowmelt reduce the risk a moisture shortage in the spring-summer period. In Kazakhstan, the use of long-term remote sensing data and the basics of creating space monitoring systems are most well covered in the work [8].

In general, in the context of climate change in Kazakhstan, it is expected to reduce the of snow covered area (SCA) and its earlier descent. Snow cover is particularly sensitive to temperature changes in the periphery, in the zero temperature zone. Kazakhstan belongs to the border zone, southern Kazakhstan is an area with unstable snow cover, in Northern Kazakhstan, snow still persists for 4-5 months a year and is subject to significant risks of reduction of SCA and early descent. Taking into consideration that Northern Kazakhstan provides $80 \%$ of the spring wheat yield, informing farmers becomes an urgent task. In addition, adaptation strategies recommend improved monitoring and awareness of farmers. Therefore, informing farmers about the snow cover is a win-win adaptation, since the best informing of consumers is necessary by itself, regardless of conditions.

The main purpose of this publication is to briefly describe the structure of snow cover monitoring in Kazakhstan and demonstrate the preliminary concept of the format for providing data to consumers, as a development of the ideas proposed by L. F. Spivak [8].

\section{Results and discussion}

\subsection{Recognition and operational mapping of snow cover borders}

The Normalized Differential Snow Index (NDSI) is used for snow cover recognition, which takes into account the high reflectivity of snow in the visible range and the low emissivity in the near-infrared (IR) range [9]. Currently, the vector borders of the snow cover are available daily for download on the website worldview.earthdata.nasa.gov 1-2 times a day based on Aqua and Terra MODIS data with a delay of 1 day. This time lag is not critical for the tasks of this monitoring. Surely, these NDSI products contain inaccurate and erroneous areas occupied by snow cover (a typical example is how salt from the bottom of the Aral sea is classified as snow), but in generally, the border of the snow cover is distinguished with acceptable accuracy. In General, this task is evaluated as solved.

The problem of assessing changes is solve by daily monitoring of SCA, which allows you to assess the dynamics of snow cover loss.

\subsection{Monitoring the seasonal dynamics of snowmelt}

The technology for analyzing the seasonal dynamics of snowmelt provides for spatial comparison of operational maps and assessment of changes in SCA, snow-free territories, and active snowmelt zones. It should be noted that the snowmelt is uneven. The comparison results are drawn up in the form of maps and diagrams that reflect changes in the area of zones, the analysis of which allows you to estimate the rate of snowmelt and identify areas of accelerated snowmelt. This information is useful for predicting the most critical areas of flood development and can be used to estimate the amount of snow that has melted.

At the end of the snowmelt process, a final map is formed (Figure 1) on the entire territory of Kazakhstan by combining daily vector data on the boundaries of the snow cover, which is then used to analyze the inter-seasonal dynamics of snowmelt. 
In General, at this level, based on the results of the analysis of snowmelt, it is advisable to form a Bulletin once a decade that reflects the sub-decadal dynamics of snowmelt in the

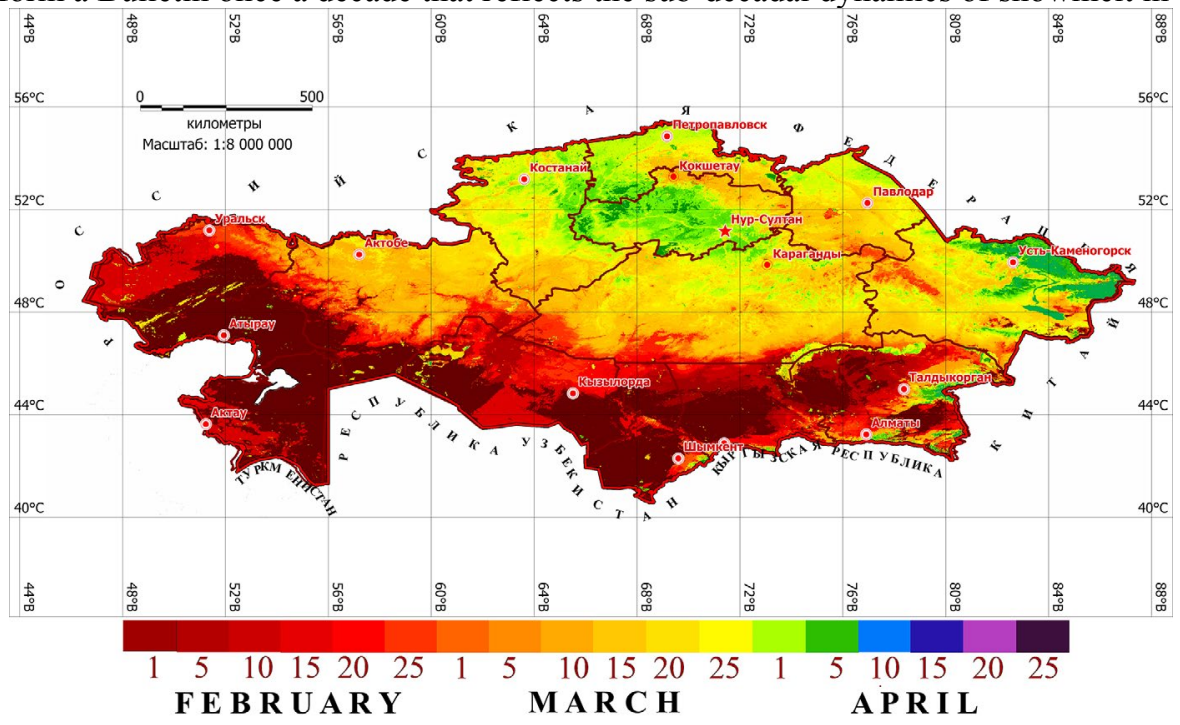

Fig. 1. Snow melting map for 2020 .

current season. The optimal periodicity of the Bulletin is 1 time per decade according to the "sliding window" principle.

\subsection{Analysis of long-term dynamics of snowmelt}

The SCA obtained for a long-term period allow the formation of long-term data series. Figure 2 shows the dynamics of changes of SCA obtained from MODIS data. There is a trend towards a reduction of SCA. The most likely cause is global warming. Long-term data series allow statistical comparisons of different seasons.

\section{SCA}

in, $\%$ of the territory of Kazakhstan

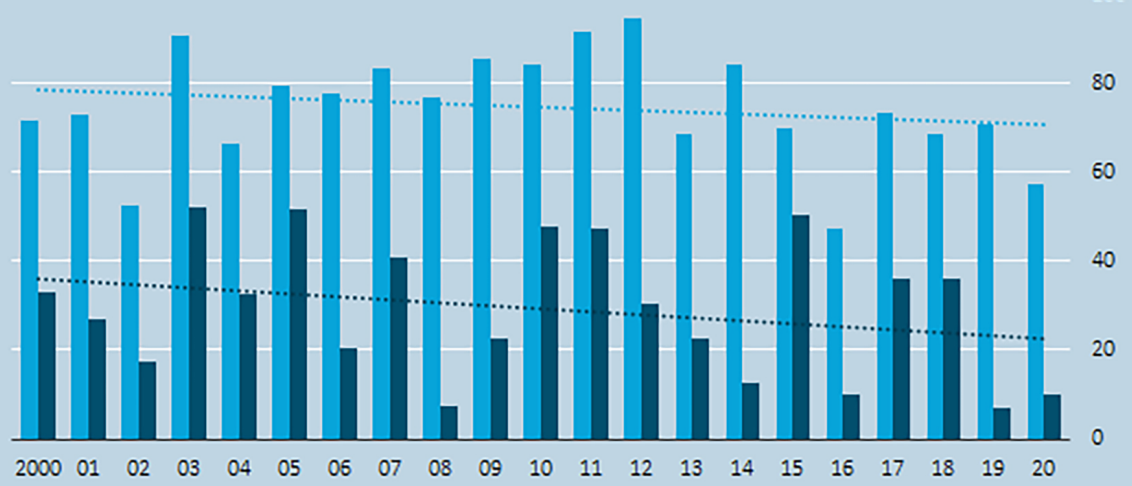

Source: Azamat Kauazov

Fig. 2. Maximum SCA in the first ten days of March and April in 2000-2020, as a percentage of the territory of Kazakhstan. 
Off-season monitoring includes:

- comparative analysis of snow cover dynamics in the current and previous seasons to assess the risk of flooding of territories;

- analysis of spatio-temporal patterns of snow cover loss and development of droughts over a multi-year period.

A comparative analysis of the results of monitoring snowmelt in the current season and in previous years allows us to estimate the rate of snowmelt relative to the average annual norm (fast, normal, slow) and select a "year analog" similar to the rate of snowmelt, which makes it possible to predict the development of the situation in the current year according to a similar scenario.

The results of the analysis are issued in the form of a special bulletin that provides an opportunity to compare current conditions with previous years. The consumer should have a visual opportunity to assess the differences in rate of snow melting, find out how sooner or later the snow melts, and accordingly prepare for sowing.

It is equally important to be able to objectively compare the dynamics of snowmelt in the current season with long-term observations, choose the most suitable "years analog" and, taking this into account, specify the sowing dates.

Figure 3 shows an approximate concept design of the bulletin as a result of comparing the dates of snowmelt in the current season with the average annual norm, indicating the zones of early and late snowmelt.

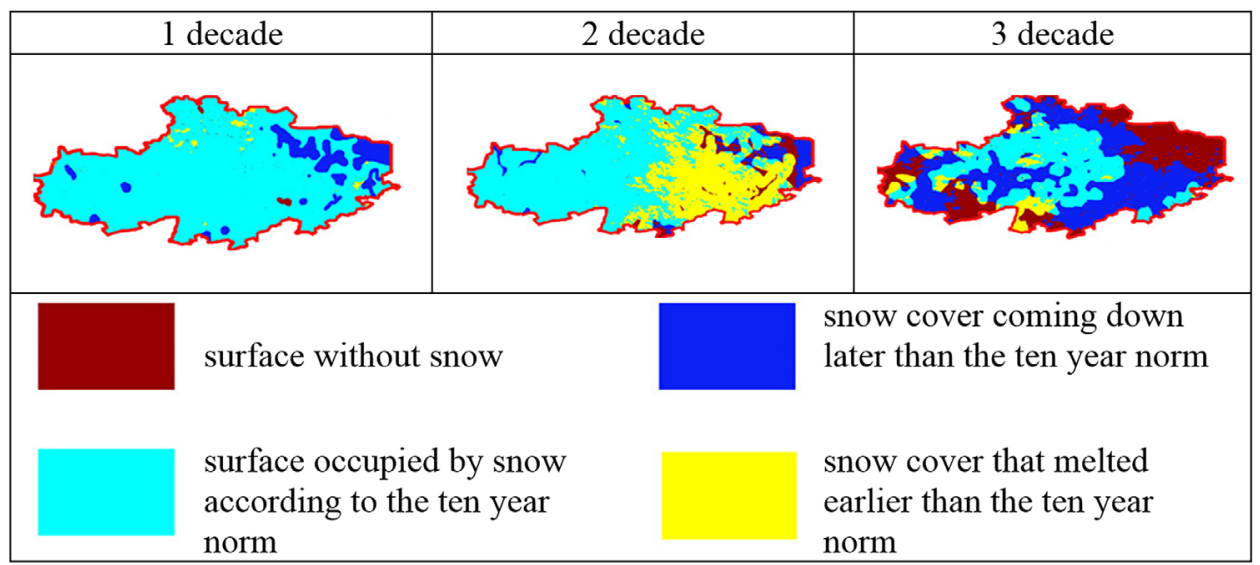

Fig. 3. Analysis of the dynamics of snowmelt with a ten-year norm.

Monitoring the dates and rates of snowmelt is also important because it allows you to indirectly predict potential droughts. It is known that the first half of the vegetation period of plants largely depends on snow reserves, or rather on the spring moisture reserve in the soil. Comparison of vegetation maps (NDVI) and snow cover maps shows that areas with low snowmelt are potential sources of drought events [10]. Early snowmelt and, accordingly, early spring, cause an early start of vegetation, while the maximum vegetation also shifts to the early dates: end of may-beginning of June, although in normal years the peak vegetation occurs a month later. Rapid development of vegetation, coupled with low initial soil moisture reserves, causes a lack of moisture and the subsequent development of drought.

It is obvious that consumers are interested in the final product, the moisture content in the snow cover, or the soil moisture content. Snow bulletins are planned to be implemented on the basis of the national hydrometeorological service of Kazakhstan RSE 
«Kazhydromet». The proposed approach for estimating the area of snow cover is only an initial stage. The objective complexity of the snow cover, the lack of necessary satellite data/sensors, as well as the lack of models that accurately describe all processes in the snow cover does not allow using data on moisture storage with sufficient accuracy and reliability-figure 3. The difficulties and prospects of remote snow water equivalent (SWE) assessment are described in more detail in the SnowEx project.

Some hopes in the near future are associated with the launch of a Chinese satellite as part of the WCOM project. FEWS NET data is also promising if it is calibrated. A comparative analysis of FEWS NET SWE data and ground-based observations has shown that there are significant absolute and relative errors.

Besides, Kazhydromet is working on the adaptation and calibration of hydrological and numerical models, for example, the MODSNOW model is being improved and the SNOW17 model can be adapted in the future.

Thus, despite some difficulties in monitoring snow cover at the global level, at the regional level, there is hope for a significant improvement in the snow cover monitoring system, increased preparedness and adaptation.

\section{Conclusion}

Monitoring is not an end in itself. The data set must be analyzed to get new information. At the same time, it is important not only to analyze and summarize the monitoring results, but also to present them in a convenient and visual form. Since data on snow cover are very diverse in the spatial and temporal aspect and may differ significantly from year to year, therefore, it is most appropriate to present the results of space monitoring of snow cover in a comprehensive, as generalized as possible, which can help attract a wide range of consumers to the monitoring results. Against the background of a reduction of snow covered area, the proposed three-level system of space monitoring of snow cover seems to be a logical and integral result for the formation of a full-fledged final product. In addition, awareness-raising activities for farmers and the public are an important area of climate change adaptation and capacity-building.

\section{References}

1. A.M. Kauazov, A.C. Dara at all. Sovremennye problemy distantsionnogo zondirovaniya Zemli iz kosmosa (Sovr. Probl. DZZ Kosm.), 13. № 1, p. 161-168, (2016) DOI: 10.21046/2070-7401-2016-13-1-161-168

2. A. G. Terekhov, N. I. Ivkina, N. R. Yunicheva, I. S. Vitkovskaya, A. G. Eltay, Sovremennye problemy distantsionnogo zondirovaniya Zemli iz kosmosa (Sovr. Probl. DZZ Kosm.), 17, № 2, p. 101-113, (2020) DOI: 10.21046/2070-7401-2020-17-3-3140.

3. A.G. Terekhov, N.N. Abaev, N.R. Unicheva, Sovremennye problemy distantsionnogo zondirovaniya Zemli iz kosmosa (Sovr. Probl. DZZ Kosm.), 16, № 5, p. 351-355, (2019) DOI: 10.21046/2070-7401-2019-16-5-351-355.

4. V. G. Salnikov, G. K. Turulina, E. A. Talanov, S. E. Polyakova, A. M. Kauazov, V. V. Vorotyntseva, Proceedings of the Hydrometeorological Research Center of the Russian Federation, 358, p 133-144, (2015)

5. A. G. Terekhov, Gidrometeorologiya i ekologiya, 90, № 3, p. 29-36, (2018)

6. M. A. Lokoshchenko, Meteorologiya i Gidrologiya, 6, p. 71-82, (2005)

7. V. V. Popova, Meteorologiya i Gidrologiya, 8, p.78-90, (2004) 
8. L. F. Spivak, Methodological guide: Fundamentals of creating space monitoring systems, 2, p.88, (2010)

9. I. A. Neustadt, Sovremennye problemy distantsionnogo zondirovaniya Zemli iz kosmosa (Sovr. Probl. DZZ Kosm.), 3, p.359-365, (2006)

10. E.A. Zakarin, L. F. Spivak, Remote sensing methods in agriculture in Kazakhstan, p.230 (1992) 